\title{
Contraception and Development: A Unified Growth Theory
}

by

\section{Holger Strulik}

Discussion Papers on Business and Economics

No. $7 / 2014$

FURTHER INFORMATION

Department of Business and Economics

Faculty of Business and Social Sciences

University of Southern Denmark

Campusvej 55

DK-5230 Odense M

Denmark

Tel.: +45 65503271

Fax: +456550 3237

E-mail: lho@sam.sdu.dk

http://www.sdu.dk/ivoe 


\title{
Contraception and Development: A Unified Growth Theory
}

\author{
Holger Strulik*
}

April 2014

\begin{abstract}
This study investigates the interaction of the use of modern contraceptives, fertility, education, and long-run growth. It develops an economic model that takes into account that sexual intercourse is utility enhancing and that birth control by modern contraceptives is more efficient and more costly than traditional methods. The study shows how a traditional economy, in which modern contraceptives are not used and fertility is high, gradually converges towards a high growth regime, in which couples use modern contraceptives. Innovations in contraceptive technology at later points in time speed up the fertility transition and the convergence to steady growth. Utility enhancing sexual intercourse provides a "natural" explanation for why net fertility decreases with income. Lower prices or higher efficacy of contraceptives are conducive to an earlier onset of the fertility transition and a quicker convergence but do not effect economic performance (nor sexual intercourse) at the steady state.
\end{abstract}

Keywords: fertility, sex, contraceptive use, education, economic development. JEL: 040; I25; J10; N30.

\footnotetext{
${ }^{*}$ University of Goettingen, Department of Economics, Platz der Goettinger Sieben 3, 37073 Goettingen, Germany; email: holger.strulik@wiwi.uni-goettingen.de. I would like to thank Carl-Johan Dalgaard, Sophia Kan, Lars Loenstrup, and Klaus Prettner for comments.
} 


\section{INTRODUCTION}

There exists a vast literature on child demand and demographic-economic development built upon the idea that households spend part of their income on have children. The idea that households spend income in order to not have children, however, has received relatively little attention in the literature. This paper acknowledges that sexual intercourse (hereafter referred to as sex) is a utility enhancing activity and develops a theory of demand for children as well as for contraceptives. The use of modern contraceptives allows households to experience utility from sex without a proportional increase in child births. Consequently, family size becomes a function of the price and efficacy of contraceptives. A smaller family size requires less time dedicated to child rearing time by the parents, and part of the released time is spent on children's education. Through this channel, the cost and efficacy of contraceptives have a significant impact on the onset of the fertility transition and on the speed of convergence towards a steady state of high economic growth.

This study contributes to the literature on unified growth theory by investigating the take-off from quasi-stagnation to modern growth and by emphasizing the importance of the fertility transition and the child quality-quantity trade-off for successful long-run development. ${ }^{1}$ It extends the literature by exploring the role of sexual desire (besides the desire for fertility) and the impact of price and efficacy of contraceptives for the onset and speed of the fertility transition. The existence of contraceptives creates multiple equilibria of which the equilibrium of high growth is potentially latent. When households start using modern contraceptives, a threshold is crossed such that with rising income households gradually substitute child quantity with child quality (education). Crossing this threshold may be caused exogenously (by a sufficiently strong decline of the price for contraceptives) or endogenously (by gradually rising household income and education). The steady-state growth rates at the low-growth equilibrium and at the highgrowth equilibrium are independent from the price and efficacy of contraception. Contraception only temporarily impacts on growth by initiating and accelerating the fertility transition. The fertility transition is accompanied by a "sexual revolution", i.e. sex is increases while fertility declines. A parametric increase in the desire for sex has a distinctive impact at both equilibria.

\footnotetext{
1 For unified growth see Galor and Weil (2000), Kögel and Prskawetz (2001), Jones, 2001, Lucas (2002), Galor and Moav (2002, 2006), Doepke (2004), Cervelatti and Sunde (2005), Galor and Mountford (2008), Strulik and Weisdorf (2008) and many others. See Galor $(2005,2011)$ for surveys.
} 
It increases fertility and reduces education at the low-growth equilibrium, while reducing fertility and leaving education unaffected at the high-growth equilibrium.

The happiness literature has produced compelling evidence that sex is utility enhancing (Blanchflower and Oswald, 2004). This is true for both men and women. According to a study by Kahneman et al. (2004), sex is the activity that provides the single largest amount of happiness for a sample of women in the U.S. At the same time, there is surprisingly little support for the conventional Beckerian view that utility increases with family size (Margolis and Myrskylae, 2011; Deaton and Stone, 2014). These observations may appear puzzling from a conventional economic viewpoint but they are readily explained by evolutionary psychology. By Darwinian selection, the human brain evolved to experience joy from sex before it was able to understand reproductive biology. During evolution humans had no clear notion of how sexual intercourse was related to fertility, which explains the desire for sex without the desire for (more) children and the demand for contraceptives (Wright, 1994).

The two perhaps greatest innovations of contraceptive technology, the rubber condom (1855) and the contraceptive pill (1960), happened suspiciously close to the onset of the first demographic transition and the second demographic transition in many Western countries. Some economic historians are nevertheless reluctant to make a causal connection with respect to the first fertility transition because the price of condoms was still relatively high at the end of the 19th century (Guinnane, 2011). As shown below, this view is hard to support in a heterogenous society. Allowing for heterogeneity, there will always be some couples rich enough to find contraceptives attractive even at a high price. These pioneers of the fertility transition will have less children and initiate the demographic transition and the take-off to growth. With growing income levels, contraceptive use will be adopted by poorer individuals as well, which in turn further quickens the fertility transition and convergence to modern growth. ${ }^{2}$

With respect to developing countries it is a far less contested issue that contraceptive use is a leading proximate cause of the fertility decline (e.g. Bongaarts and Potter, 1983; Westoff and Bankole, 2011; Lule et al., 2007; Darroch and Sing, 2013). There is, however, a debate about as to whether to what extent actual fertility deviates from desired fertility (Pritchett, 1994; Bongarts, 1994; Guenther and Harrtgen, 2013). Differentiating views in this respect likely

\footnotetext{
${ }^{2}$ See Livi-Bacci (1986) and Haines (1989) for evidence that the fertility transition started among the rich. By taking the price of contraption into account, the present paper provides an alternative and possibly complementing mechanism to the more common view that contraception diffused through social learning from the rich to the poor (Seccombe, 1990)
} 
Figure 1: Fertility vs. Contraceptive Prevalence Across Developing Countries 1985 - 2012

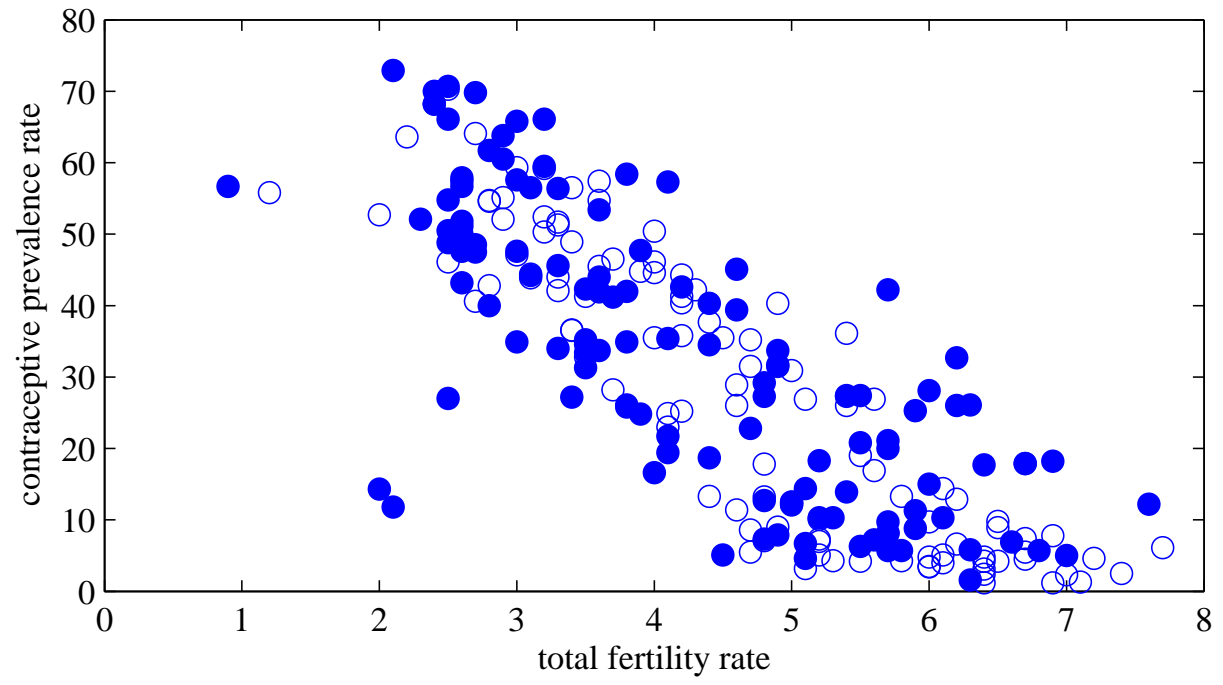

Data from available non-European DHS surveys (as of April 2014). White dots: 111 country surveys 1985-1999; blue dots: 127 country surveys 2000-2012. Fertility is the total fertility rate for the three years preceding the survey and the percentage of 1549 years old women currently pregnant. Contraceptive prevalence is the current use of modern contraception methods among currently married women. Source: ICF (2012).

originate from different views on the set of constraints that women take into account when they reveal their fertility preferences. This study assumes that couples also consider their desire for sex as well as the availability, price, and efficacy of contraceptives when they derive their constrained-optimal fertility. The point is that modern contraceptives are used in order to reduce fertility. This fact is evident from Figure 1, which shows a strong negative association between the total fertility rate and the prevalence rate of modern contraceptives in developing countries. The data is taken from the available DHS surveys (ICF, 2012). White dots represent data from surveys taken from 1985-1999, and blue dots represent surveys from 2000-2012. The association seems to be almost time-invariant since the 1980s. The fertility transition moves in sync with intensified use of modern contraceptives.

Prevalence of contraceptive use in highly developed countries is close to complete. In the US in 2002, for example, 98 percent of all women who ever had intercourse used at least one contraceptive method and about 62 percent of the 15-44 years old women were currently using contraceptives. Those not using contraceptives were mostly pregnant, or trying to become pregnant, or were unable to conceive (Mosher et al., 2004). Accounting for legal differences across US states and health policy differences across US counties, Bailey (2010, 2013) shows 
that the increase in uptake of oral contraception in the 1960s and 1970s had not only a causal impact on fertility but also a positive impact on education and income of subsequent generations.

Economic theory only recently began to take into account that sex is a utility enhancing activity. Greenwood and Guner (2010) and Fernandez-Villaverde et al. (2014) developed models of contraceptive use, pre-marital sex, and out-of-wedlock childbearing and investigated how preventive technology affected the sexual revolution and the intergenerational transmission of sexual norms. However, the relevance of contraceptive use for the fertility transition and the take off to modern growth were not investigated.

Most closely related to this paper is perhaps the study by Bhattacharya and Chakroborty (2014) on the fertility decline in Victorian England. According to their model, sex is not utility enhancing but contraceptives are needed to push fertility below a natural maximum. The use of contraceptives, in turn, is not costly in monetary terms but utility reducing. Using modern contraceptives is associated with a higher base disutility and less steeply increasing disutility with intensity of use. The presence of contraception implies that the utility function becomes non-homothetic and results in demand for children that is first increasing and then decreasing in income. By taking into account matching of spouses and social diffusion of contraceptive use, their model is in some sense richer than the present one. On the other hand, economic growth is absent or constant, whereas the present paper establishes a feedback mechanism between the gradual uptake of contraceptives and the gradual increase of economic growth over the last century. The interference with the utility function makes Bhattacharya and Chakroborty's results harder to derive explicitly and harder to assess intuitively. The present paper follows a more direct approach in order to highlight the importance of contraceptives for the fertility transition. Inspired by happiness research and evolutionary psychology, it acknowledges that sex is utility enhancing and that contraception is costly in monetary terms. This allows for the derivation of all the results in closed form as well as for an intuitive interpretation. It also allows for a straightforward numerical calibration of the model.

This paper also contributes to the general discussion of the income-fertility nexus. That there exists a strong negative association between income and fertility across countries, within countries over time, and within countries across households is relatively well-known (e.g. Jones and Tertilt, 2008; Herzer et al., 2013). What is perhaps less well-known is that it is surprisingly difficult to explain the negative association at the household level. As demonstrated in detail by 
Jones et al. (2010), the result of a negative income-fertility nexus usually requires non-standard manipulations of the utility function or the introduction of special assumptions like the presence of exogenous non-labor income. As shown below, a negative association between fertility and income emerges "naturally" after acknowledging that sex is a utility enhancing activity and that contraception is costly.

This paper is organized as follows. Section 2 sets up the model, computes the threshold for contraceptive use and its comparative statics, and compares behavior of households with and without use of contraceptives. Section 3 investigates the implied macro-economic performance at the steady states. Section 4 calibrates the model and assesses the quantitative impact of contraceptive use for the transition to modern growth. Section 5 concludes.

\section{THe Model}

Consider an economy populated by a measure one of households and a measure one of competitive firms. At any given time, firms produce output according to the production function $y_{t}=h_{t} \ell_{t}$, in which $\ell_{t}$ is employment and $h_{t}$ is human capital of the workforce. The wage per unit of human capital is thus unity and potential income of households is given by their endowment of human capital $h_{t}$.

Households consist of couples who cooperatively maximize utility from consumption, from having surviving children, from future income of their children, and from having sex. We measure all variables in units per parent, such that $n_{t}$ is the number of births per parent, and $c_{t}$ is consumption expenditure per parent, etc. In order to derive an analytical solution, the household utility function is assumed to be separable and logarithmic. It reads

$$
U=\log c_{t}+\alpha \log \left(\pi_{t} n_{t}\right)+\gamma \log h_{t+1}+\sigma \log s_{t}
$$

in which $h_{t+1}$ is the human capital (future income) per child, $\pi_{t}$ is the child survival rate, and $s_{t}$ is the household time devoted to sex. Besides its last element, the utility function is standard in unified growth theory. As shown in the Introduction, there is strong support from the happiness literature as well as from evolutionary psychology that sex is utility enhancing. The parameter $\sigma$ measures the couples' desire for sex.

For simplicity, we measure sex $s_{t}$ such that a unit of $s_{t}$ implies a unit of $n_{t}$ without the use of modern contraceptives. This number may be thought of as already taking into account costless 
traditional methods of contraception, like breastfeeding or withdrawal. For completeness, we note the existence of an upper limit of fertility, given by female reproductive capacity, $\bar{n}$. In the analysis below, however, fertility will be assumed to always lie below its biological maximum, in line with the historical evidence. Using a unit of modern contraceptives prevents the birth of $\mu$ children. The parameter $\mu$ thus controls the effectiveness of modern contraceptives. Taking the corner solution into account, the number of births is

$$
n_{t}=\min \left\{s_{t}-\mu u_{t}, \bar{n}\right\}
$$

in which $u_{t}$ is household demand for modern contraceptives.

Human capital is produced according to the production function

$$
h_{t+1}=A e_{t} h_{t},
$$

in which $e_{t}$ is the time spent on education per child. The next period's human capital is thus a positive function of education and the human capital endowment of adults. The linearity in $e_{t}$ is innocuous and could be avoided without loss of generality. The linearity in human capital is essential for the model to create perpetual growth at the long-run steady state but is inessential for the results on contraceptive use and their implications for the fertility transition. See Strulik et al. (2013) for a motivation of the linearity assumption.

We assume that the probability that a child survives to adulthood $\pi_{t}$ is taken as given at the household level and not partly controlled through expenditure on child health and nutrition (as in Strulik, 2008 and Strulik and Weisdorf, 2014). We also treat children as a continuous number in order to avoid problems of precautionary child-bearing (as in Kalemli-Ozcan, 2002, 2003). These simplifying assumptions are only justified by the different focus of the present paper. In fact, it will be shown below that the uptake of modern contraceptives operates as a stand-alone mechanism taking child survival as constant. Adding a feedback effect between parental human capital (income) and child survival adds more realism to the quantitative experiments but it is not essentially driving any of the results. As Bhattacharya and Chakraboty (2014) and many related studies we assume that child rearing costs as well as education costs are incurred only for surviving children. Child rearing costs $\phi$ and education investment $e_{t}$ are measured in terms of income lost due to the time spent on rearing and education per child. 
Households are endowed with one unit of time per adult and face the budget constraint

$$
h_{t}\left(1-\phi \pi_{t} n_{t}-e_{t} \pi_{t} n_{t}-\tau s_{t}\right)=p u_{t}+c_{t} .
$$

in which $p$ is the price of modern contraceptives. The price is taken as given by households but it may occasionally change. One can imagine that $p$ was infinitely large at times when modern contraceptives were not yet available. Notice that there is also a cost in terms of time for of sex, denoted by $\tau>0$. This is a necessary assumption in order to prevent sex from increasing without limit in a growing economy. An arbitrarily small cost in time is sufficient to achieve asymptotically constant sex. Alternatively, we could use a satiation level or a physical upper limit for sex without changing the results. We refer to human capital $h_{t}$ also as potential income and to the expression on the left-hand side of (4) as actual income, i.e. human capital multiplied by labor supply.

Households maximize (1) subject to (2)-(4), given non-negativity constraints on all variables. Additionally, we assume $\gamma<\alpha$. The assumption ensures that parents prefer to have children even if they could be avoided without cost (i.e. for $p=0$ ), see below. This plausible restriction prevents unnecessary case differentiation. Notice that the utility function is homothetic and that there exist no "tricks" like, for example, a kink in the education function. Nevertheless, fertility and education will be income dependent because of the presence of costly contraceptives. The interior solutions for consumption, fertility, education, and contraceptive use, and sex are:

$$
\begin{aligned}
c_{t} & =c_{t}^{M} \equiv \frac{h_{t}}{1+\alpha+\sigma} \\
n_{t}=n_{t}^{M} & \equiv \frac{(\alpha-\gamma) \mu h_{t}}{(1+\alpha+\sigma)\left[\left(\phi \pi_{t} \mu h_{t}-p\right]\right.} \\
e_{t} & =e_{t}^{M} \equiv \frac{\gamma\left(\phi \pi_{t} \mu h_{t}-p\right)}{(\alpha-\gamma) \pi_{t} \mu h_{t}} \\
u_{t} & =u_{t}^{M} \equiv\left(\frac{\sigma}{\mu \tau h_{t}+p}-\frac{\alpha-\gamma}{\phi \pi_{t} \mu h_{t}-p}\right) \frac{h_{t}}{1+\alpha+\sigma} \\
s_{t} & =s_{t}^{M} \equiv \frac{\sigma \mu h_{t}}{(1+\alpha+\sigma)\left(\tau \mu h_{t}+p\right)} .
\end{aligned}
$$

A superscript $M$ identifies the optimal choice of a variable at an equilibrium where modern contraceptives are used.

Inspecting the relevant first-order derivatives of (6)-(9) proves the following proposition. 
Proposition 1. At the interior solution of the households' problem we observe the following comparative statics:

- An increase in human capital (income) $h_{t}$ reduces fertility and increases consumption, education, contraceptive use, and sex.

- An increase in child survival $\pi_{t}$ reduces fertility and increases education per child and the use of contraceptives. It leaves sex unaffected.

- A reduction in the price of contraceptives $p$ reduces fertility and increases education, contraceptive use, and sex.

- An increase in the desire for sex $\sigma$ increases contraceptive use and decreases fertility. It leaves education unaffected.

- An increase in the efficacy of contraception $\mu$ increases contraceptive use, sex, and education and it decreases fertility.

Most of these comparative statics are expected. The most surprising and "non-Darwinian" result is that $\partial n / \partial \sigma<0$. Couples who like sex a lot, have less kids. This is the case because sex is expensive when modern contraceptives are used such that couples partly substitute child costs when they increase their sexual activity. The negative association between income and fertility arises because better educated and richer adults can afford costly contraceptives and prefer a smaller family. A smaller number of children requires less child rearing time, and the saved time is invested in the children's education.

Proposition 2. Modern contraceptives are not used $\left(u_{t}=0\right)$ if human capital (income) is sufficiently low compared to the price of modern contraceptives that is if

$$
h_{t} \leq \bar{h} \equiv \frac{p(\alpha-\gamma+\sigma)}{\mu\left[\sigma \phi \pi_{t}-(\alpha-\gamma) \tau\right]} .
$$

Ceteris paribus, the threshold $\bar{h}$ is

- increasing in the price of contraceptives $p$ and the desire for children $\alpha$

- declining in the child survival rate $\pi_{t}$, the efficacy of contraceptives $\mu$, the desire for sex $\sigma$, the time cost of child rearing $\phi$, and the desire for education $\gamma$.

The proof evaluates $(8)$ for $u_{t} \leq 0$, i.e. when the non-negativity constraint on contraceptive demand is binding. In line with the literature, the proposition confirms both low income (human capital) and high cost of contraceptives (approximating as well difficult access) as causes of the 
lack of demand for contraceptives (Ainsworth et al., 1996; Gakidou and Vayena, 2007). Yet it is also true that non-users of contraceptives have more children than users with the same preferences (see Proposition 3 below). In a questionnaire, non-users may thus state that they do not use contraceptives because they want more children (Prittchett, 1994; World Bank, 2007). The ultimate reason, however, is not found in preferences, but in constraints. Given higher education or income, or lower costs of contraceptives, the same person would prefer to use contraceptives and desire a smaller family size. The proposition also identifies, like Bhattacharya and Chakraborty (2014), the prevalence of high child mortality as an obstacle to contraceptive use. The reason here is plainly that in a high mortality environment, less contraception is needed to achieve a given family size.

The corner solution without use of modern contraceptives is obtained as:

$$
\begin{aligned}
n_{t} & =n_{t}^{T} \equiv \frac{\alpha-\gamma+\sigma}{(1+\alpha+\sigma)\left(\phi \pi_{t}+\tau\right)} \\
e_{t} & =e_{t}^{T} \equiv \frac{\gamma\left(\phi \pi_{t}+\tau\right)}{\pi_{t}(\alpha-\gamma+\sigma)} \\
s_{t} & =s_{t}^{T} \equiv \frac{\alpha-\gamma+\sigma}{(1+\alpha+\sigma)\left(\phi \pi_{t}+\tau\right)} .
\end{aligned}
$$

and $c_{t}=c_{t}^{T}=c_{t}^{M}$. A superscript $T$ indicates an equilibrium at which only traditional methods of contraception are used. Notice parents invest into education at the traditional equilibrium but education does not rise with income. Education at the corner can best be conceptualized as children learning the basic techniques of a trade or of subsistence agriculture. Comparing the traditional and the modern equilibrium, we find:

Proposition 3. At the traditional equilibrium, fertility is higher and education and sex are lower than at the modern equilibrium.

The proof begins with noting from Proposition 2 that the modern equilibrium fulfills $p(\alpha-$ $\gamma+\sigma)<\left[\sigma \phi \pi_{t}-(\alpha-\gamma) \tau\right] \mu h_{t}$, that is $(\alpha-\gamma)\left(\phi \pi_{t}+\tau\right) \mu h_{t}<(\alpha-\gamma+\sigma)\left(\mu \phi \pi_{t} h_{t}-p\right)$, that is $n_{t}^{M}<n_{t}^{T}$. The proofs for education and sex are analogous.

Interestingly, people enjoy less sex at the traditional equilibrium. The economic transition from a traditional society to a modern one is also accompanied by "sexual liberation". We assume that $n_{t}^{T}<\bar{n}$, which avoids unnecessary case differentiation. Inspecting the respective derivatives of (11)-(13) verifies the following proposition. 
Proposition 4. At the traditional equilibrium we observe the following comparative statics:

- An increase in human capital (income) $h_{t}$ leads to more consumption and leaves fertility, education, and sex unaffected.

- An increase in child survival $\pi_{t}$ leads to lower fertility, lower education per child $e_{t}$, and less sex $s_{t}$.

- An increase in the desire for sex $\sigma$ increases fertility and reduces education.

Notice that the model predicts very different comparative statics for the traditional society compared to the modern society. In particular, a stronger desire for sex has different consequences at the traditional and modern equilibria. At the traditional equilibrium, we observe the "Darwinian" result that a greater desire for sex increases fertility. Furthermore, decreasing child mortality reduces education at the traditional equilibrium, while increasing it at the modern equilibrium. The direction of the response of fertility to mortality changes goes in the same direction at both equilibria but, as established by the next proposition, there is a differentiated impact of child mortality on the number of surviving children.

Proposition 5. An improvement of child survival $\pi_{t}$ leads to higher net fertility $\pi_{t} n_{t}$ at the traditional equilibrium and to lower net fertility at the modern equilibrium.

The proof inspects the derivatives

$$
\frac{\partial\left(\pi_{t} n_{t}^{M}\right)}{\partial \pi_{t}}=-\frac{(\alpha-\gamma) \pi_{t} \mu h_{t}}{(1+\alpha+\sigma)^{2}\left(\phi \pi_{t} \mu h_{t}-p\right)}<0, \quad \frac{\partial\left(\pi_{t} n_{t}^{T}\right)}{\partial \pi_{t}}=\frac{(\alpha-\gamma+\sigma) \tau}{(1+\alpha+\sigma)\left(\phi \pi_{t}+\tau\right)^{2}}>0 .
$$

The result sheds new light on the debate as to whether the historical decline in child mortality could have been the causal mechanism for the demographic transition (see e.g. Cleland, 2001; Guinnane, 2011; Kalemli-Ozcan, 2003; Doepke, 2005; Galor, 2005). The solution suggested by the present model is that mortality may have contributed to the fertility decline only after the introduction of modern contraceptives. This is explained by a price mechanism that operates through the use of contraceptives. When more children survive, couples use more contraceptives to reach their ideal number of offspring, which in turn has a negative income effect on fertility. Indeed, net fertility is independent of child mortality if contraceptives are for free (or income approaches infinity), $\lim _{h_{t} \rightarrow \infty} \pi_{t} n_{t}^{M}=(\alpha-\gamma) /[(1+\alpha+\sigma) \phi]$. In the limit, the model confirms the view that child mortality is irrelevant for net fertility (Galor, 2005). Moreover, as long as the price of contraceptives is small compared to income, we expect a small effect of child 
mortality during the transition. This hypothesis is confirmed by the numerical experiments below. The crucial driver of the fertility transition is the availability and affordability of modern contraceptives. Before the uptake of modern contraceptives, net fertility rises when child survival improves.

Inspection of (7) seems to suggest that another corner solution where the non-negativity constraint on $e_{t}$ binds may exist. This, however, is not the case.

Lemma 1. There exists no other corner solution besides $u_{t}=0$ and $n_{t}=\bar{n}$.

For the proof, let $\underline{\mathrm{h}}$ denote the potential income threshold below which $e_{t}=0$, i.e. $\underline{\mathrm{h}}=p /(\phi \mu)$. Since $0<(\alpha-\gamma)\left(\phi \pi_{t}+\tau\right)$, we have $\sigma \phi \pi_{t}-(\alpha-\gamma) \tau<\phi \pi_{t}(\alpha-\gamma+\sigma)$ and thus, $\underline{\mathrm{h}}<\bar{h}$. But for $h<\bar{h}$ the corner solution (11)-(13) holds, at which education is positive. Thus, there is no solution with $e_{t}=0$. This outcome could be easily avoided by assuming that some minimum education is picked up without incurring costs. This case would create another corner solution, which is uninteresting only in the context of the present paper. ${ }^{3}$ Here we focus on the decision to use modern contraceptives and thus abstain from (artificially) introducing another corner solution.

\section{Long-Run Economic Development}

Inserting (12) into (3) we obtain the gross growth rate of the traditional economy

$$
\frac{h_{t+1}}{h_{t}}=g_{t}^{T} \equiv \frac{\gamma\left(\phi \pi_{t}+\tau\right) A}{\pi_{t}(\alpha-\gamma+\sigma)}
$$

Assume that productivity in education $A$ is large enough such that the modern society is capable of long-run growth and that child survival $\pi_{t}$ converges to unity in a perpetually growing economy. For $h_{t} \rightarrow \infty$ we obtain

$$
n_{\infty}^{T}=\frac{\alpha-\gamma}{(1+\gamma+\sigma) \phi}, \quad e_{\infty}^{T}=\frac{\gamma \phi}{\alpha-\gamma}, \quad s_{\infty}^{T}=\frac{\sigma}{(1+\alpha+\sigma) \tau}
$$

Inserting the solution for education in (3) we obtain the steady-state growth rate of the modern economy

$$
\frac{h_{t+1}}{h_{t}}=g^{M} \equiv \frac{\gamma \phi A}{\alpha-\gamma}
$$

\footnotetext{
${ }^{3}$ A detailed discussion of this corner solution is provided by Strulik et al. (2013).
} 
Sufficiently large productivity in education, namely $A>(\alpha-\gamma) /(\gamma \phi)$, ensures that the gross growth rate exceeds unity, i.e. that there exists positive long-run growth. It is a necessary and sufficient condition for the modern economy to converge towards (15) and is assumed to hold henceforth.

Proposition 6. The modern economy grows at a higher rate than the traditional economy.

This is verified by comparing (16) and (14). Inspection of the first order derivatives of the growth equations (14) and (16) verifies the following proposition.

\section{Proposition 7.}

- Growth at the traditional and modern equilibrium is increasing in the desire for education $\gamma$, the productivity of the educational system A, the time cost of child rearing $\phi$; and is declining in the desire for children $\alpha$.

- Both growth rates are independent from the price and efficacy of contraceptives.

- Growth of the traditional society $g^{T}$ is declining in the desire for sex $\sigma$ and increasing in the time cost of sex $\tau$.

- Growth of the modern society $g^{M}$ is independent from the time cost of sex and the desire for it.

Interestingly, while a high level of sexual desire does not harm growth of the modern economy, it does affect growth of the traditional economy.

The cost and efficacy of contraceptives are irrelevant for growth at the steady state for a given equilibrium of the economy. But cost and efficacy are decisive for whether an economy is situated at the traditional equilibrium regime or at the modern equilibrium. If Proposition 2 is fulfilled, the economy is situated at the traditional equilibrium. A sufficiently strong decline of the price of contraceptives or a sufficiently high increase of its efficacy would move the economy onto the modern growth path.

The transition towards the modern economy, however, does not necessarily require an exogenous impulse. In order to make the problem interesting and to build a unified growth theory, we assume in the following that $A$ is large enough such that the traditional society is growing as well, albeit at a (much) smaller rate than the modern society. This means that eventually education becomes large enough such that the threshold is crossed and the economy switches 
to the modern regime. The price and efficacy of contraceptives are decisive for how fast an economy transits from the traditional regime to the modern regime.

\section{Transition to Modern Growth}

We next explore transitional dynamics with a series of numerical experiments. For this purpose we specify a typical Western European country undergoing a fertility transition. Naturally, this attempt provides only a rough approximation of any particular country, given the simple structure of the model and the lack of extensive historical data on contraceptive use and sexual activity. However the numerical experiments are sufficient for exploring the basic mechanisms and to roughly assess the quantitative importance of contraception. First, I set child rearing $\operatorname{costs} \phi$ to 0.15 , according to Haveman and Wolfe (1995) and set $\alpha$ arbitrarily equal to 1.5. I then calibrate the remaining parameters such that the modern economy grows at an annual rate of 2 percent at the end of the 20 th century (steady state 2.2 percent), the traditional economy grows at a rate of 0.3 percent, fertility per couple approaches unity in the modern economy (convergence towards a stationary population), and modern couples at the end of the fertility transition have twice as much sex as traditional couples. ${ }^{4}$ This provides the estimates $\gamma=1.47$, $\sigma=0.53, A=4.1$, and $\tau=0.038$.

As shown above, price and efficacy of contraceptives do not affect the steady state. I use the data in Table 2 of Greenwood and Guner (2010) to obtain a first estimate of $\mu$. For this purpose, I assume that the traditional method consists of an average of no contraception at all (failure rate 0.85 percent) and withdrawal (failure rate 0.225 ), providing a failure rate of the traditional method of 0.53. For the effectiveness of condoms, I use an average between rubber condoms (failure rate 0.45) and latex condoms, which became available in the 1920s (failure rate 0.175). This provides a failure rate of 0.31 , and an estimate of $\mu=(1-0.31) /(1-0.53)=1.46$. Finally I set the initial time to the year 1400 and the initial endowment $h(0)$ to 10 . I then determine $p$ such that modern contraceptives are used for the first time in 1900, i.e. with a delay of two

\footnotetext{
${ }^{4}$ Sensitivity analysis confirms that results do not respond to the scale of $\alpha$, as long as the other parameters are adjusted to fulfil the conditions on steady-state growth and fertility. Likewise, assuming a different size of sexual liberation leads to a readjustment of the estimated parameters, and leaves the time paths for all variables but $u_{t}$ and $s_{t}$ unaffected.
} 
Figure 2: Long-Run Adjustment Dynamics
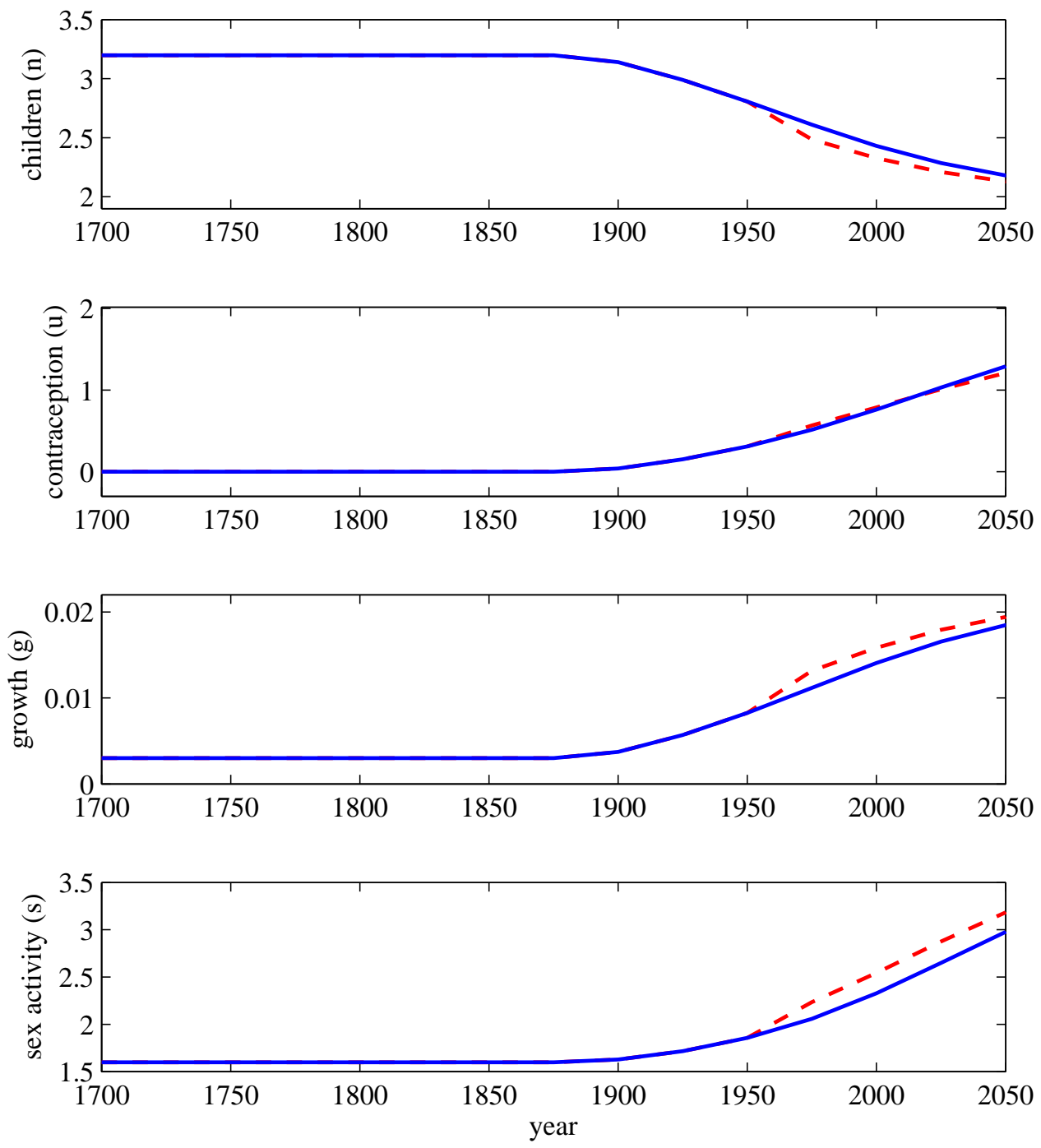

Dashed lines: $\mu$ rises from 1.46 to 1.75 in the year 1960.

generations after the invention of vulcanized rubber (patented in 1844) and the introduction of the rubber condom. This provides the estimate $p=3.3 .^{5}$

After running the numerical experiments, I convert the measure of every variable from pergeneration to per-year in order to facilitate comparison with the real evolution of these variables. For this purpose I assume that a generation takes 25 years. The figures show fertility per couple (i.e. $2 n$ ), which corresponds in practice with the total fertility rate.

\footnotetext{
${ }^{5}$ Notice that this procedure is consistent with the idea that modern contraceptives were not available before the mid-19th century. When the threshold (10) is binding for $\mu=1.46$ and $p=3.3$, it is of course also binding for higher prices and for any lower values of the efficiency parameter; capturing (much) less price-efficient contraceptives than condoms.
} 
For the first experiment I counterfactually assume that the child survival rate stays constant at unity. This experiment is useful in order to establish contraceptive use as a stand-alone mechanism that operates independently from child mortality. Blue (solid) lines in Figure 2 show the implied evolution of fertility, contraceptive use, annual growth of potential income (of human capital), and sex. The uptake of contraceptives in the late 19th century sets in motion a virtuous circle of development. It leads to less fertility, more education, and higher growth. Annual economic growth rises from 0.3 percent before the transition to about 1.4 percent in the year 2000. The model predicts that households in 1925 spend about 3 percent of their income on modern contraceptives. ${ }^{6}$ This figure somewhat underestimates the real cost when compared with the observation that "in the early twentieth century, a year's supply of condoms cost a Berlin worker the equivalent of ten to fifteen days of wages" (Brown, 2009, cited according to Guinnane, 2011; 10/250 = 4 percent).

The next experiment concerns the introduction of oral contraceptives in 1960. Using the same methodology as above and the data from Table 2 in Greenwood and Guner (2010) provides a new estimate for $\mu=(1-0.075) /(1-0.53)=1.96$ from 1960 onwards. The implied results, assuming that $p$ remains constant, are shown by dashed lines in Figure 2. The first generation that takes up oral contraception are the adults of 1975 . The fertility transition accelerates somewhat and the economy adjusts somewhat faster towards the steady-state. Annual economic growth is predicted to be 1.6 percent in the year 2000 .

We next consider the results under evolving child mortality. For this purpose, I assume that $\pi_{t}$ rises from 0.7 in the first half of the 19th century, to almost unity at the end of the 20th century. A parsimonious way to do this is to relate child survival to income of the parent such that $\pi_{t}=\max \left\{0.7,1-\exp \left(-b h_{t}\right)\right\}$. I set initial income $h_{0}$ and $b$ such that the mortality transition begins in 1825 and almost ends in 2000 (child survival rate 0.985 in 2000). This provides the estimate $b=0.038$. I take all parameters from the benchmark model and re-estimate $p$ such that modern contraceptives are first used in 1900. This provides a re-adjustment of $p$ from to 3.3 to 2.4. The break-even price of contraceptives has to be lower than in the benchmark run because households invest less in education when child survival is uncertain. Consequently, economic growth is lower and at any given time the level of human capital and income is lower than for the benchmark run.

\footnotetext{
${ }^{6}$ The expenditure share of contraceptives is computed as $p u_{t} / y_{t}$, in which $y$ is household income, $y=h[1-\pi(\phi+$ $\left.\left.e_{t}\right) n_{t}\right]$.
} 
Figure 3: Long-Run Adjustment Dynamics: Evolving Child Mortality
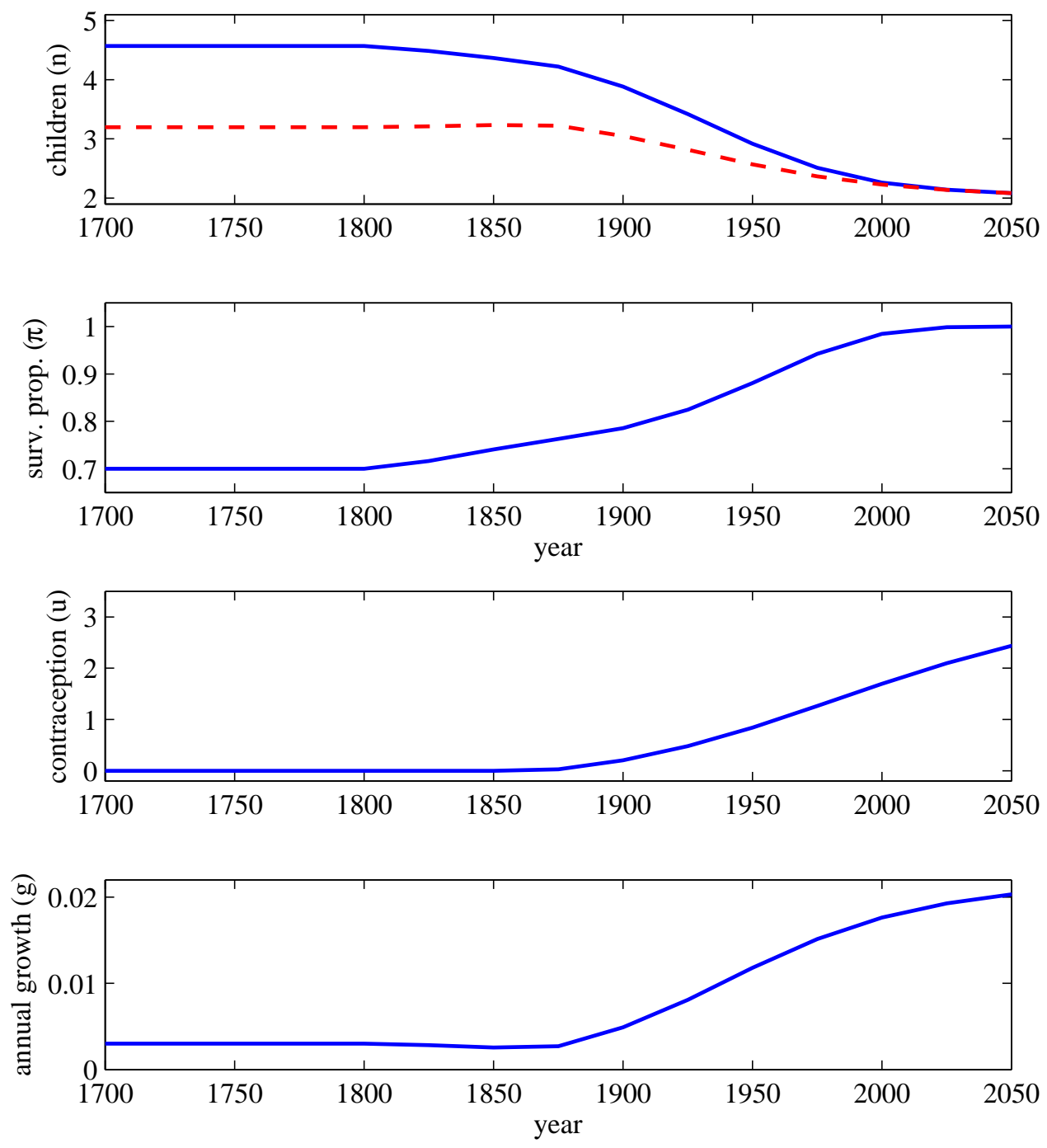

Top panel: born children (solid line) and surviving children (dashed line) per couple.

Results are shown in Figure 3. The trajectories look very similar to the ones of Figure 2. The introduction of endogenous mortality improves the prediction of fertility, which is now 4.7 children per couple (instead of 3.2), a figure closer to actual fertility in most Western countries at the dawn of the fertility transition. The main takeaway, however, is that the mortality decline does not initiate the fertility transition. In the years after the onset of mortality decline and before the take up of modern contraceptives, net fertility actually rises somewhat. This increase is almost invisible in Figure 3 (but see Proposition 5). Only after the take up of contraceptives does fertility start to decline, and education and economic growth take off.

Finally we consider a stratified society. This numerical experiment is useful to invalidate the argument that contraceptives could not have had an impact on the historical fertility decline 
and economic development because the initial price was too high to make them affordable to the average citizen. The argument is invalid because it is sufficient that some rich citizens take up modern contraception in order to set the virtuous cycle of declining fertility, rising education, and rising economic growth into motion.

In order to establish this result, I assume, for simplicity, that society is subdivided into three classes: the rich, the middle, and the poor, which differ in their initial endowments of $h$. I allow for spillovers in education such that (3) is replaced by

$$
h_{t+1, j}=A e_{t, j} h_{t, j}^{\lambda} \bar{h}_{t}^{1-\lambda}
$$

in which $e_{t, j}$ and $h_{t, j}$ are education and human capital of class $j$ at time $t$, and $\bar{h}_{t}$ is average education at time $t, \bar{h}_{t}=1 / L_{t} \sum_{j=1}^{3} h_{t, j} \ell_{t, j}$. The size of the classes evolves according to $\ell_{t+1, j}=$ $n_{t, j} \ell_{t, j}$ and where $L_{t}=\sum_{j=1}^{3} \ell_{t, j}$ is aggregate population size. I keep all parameter values from the previous experiment, but adjust $b$ to 0.0047 and $p$ to 2.7. I set the initial endowment and the initial population sizes in the year 1000 such that the rich take up modern contraceptives at the end of the 19th century. I also set $\lambda$ such that the middle class starts using contraceptives with a one period delay. This provides the estimates $\lambda=0.92$ and $h_{0}=(6,15,24)$, and $\ell_{0}=$ $(12.5,4,1.25)$.

Results are shown in Figure 4. The rich (red line) start using modern contraceptives in 1990, implying that at that time, $7 \%$ of the population were using contraceptives. This sets in motion the virtuous cycle of rising education. The onset of successful development, however, is hardly visible in aggregate growth (see the bottom panel) because the majority of the population is not yet using contraceptives. Consequently, net fertility of the middle and lower class is rising because of declining mortality (see the second panel from above). One generation later, in 1925, the middle class (green line) starts using contraceptives such that at that time, $29 \%$ of the population are using them. Another generation later, in 1950, the relative price of contraceptives has declined enough such that the poor (blue line) start using them (implying an acceptance rate of 100\%). These predictions coincide roughly with Woods' (2000) estimates for England and the values imputed by Bhattacharya and Chakraborty (2013). Notice that the stratified society provides the prediction that contraceptive use is strongly associated with education not only over time, as in the previous experiments, but also across social strata at a given time, in line with the empirical evidence (Mosher et al., 2004). 
Figure 4: Long-Run Adjustment Dynamics: Stratified Society
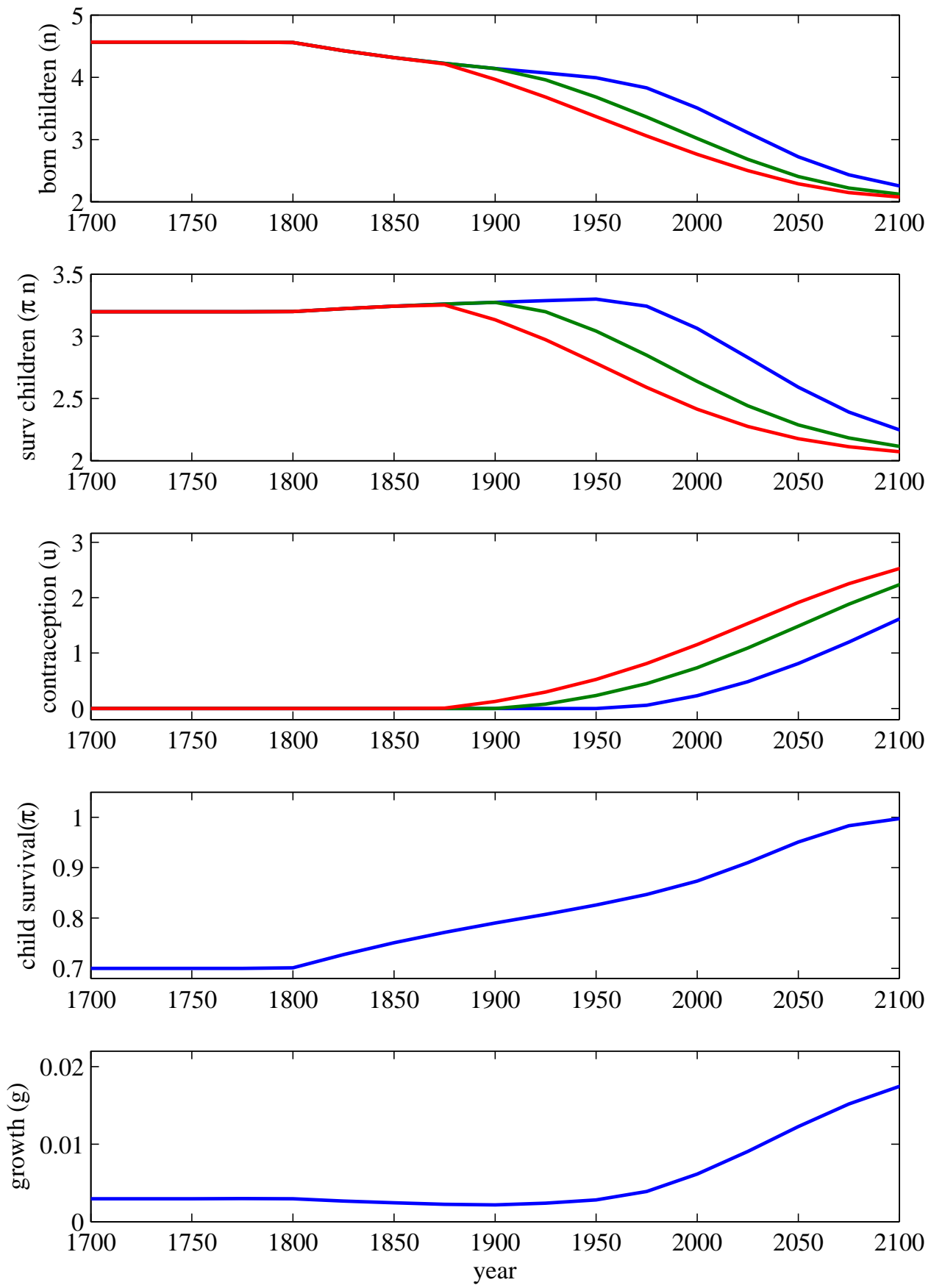

Parameter values as for Figure 3; 3 population classes; initial values $h_{0}=(6,15,24)$ and $\ell_{0}=(12.5,4,1.25)$.

The final experiment re-introduces the second contraceptive innovation in 1960 to the stratified society by setting $\mu$ to 1.46. As shown in Figure 5 , the innovation has the main effect of allowing the poor to catch-up more quickly and thus it leads to a somewhat faster speed of convergence of the economy towards the steady-state. 
Figure 5: Long-Run Adjustment Dynamics: Stratified Society II
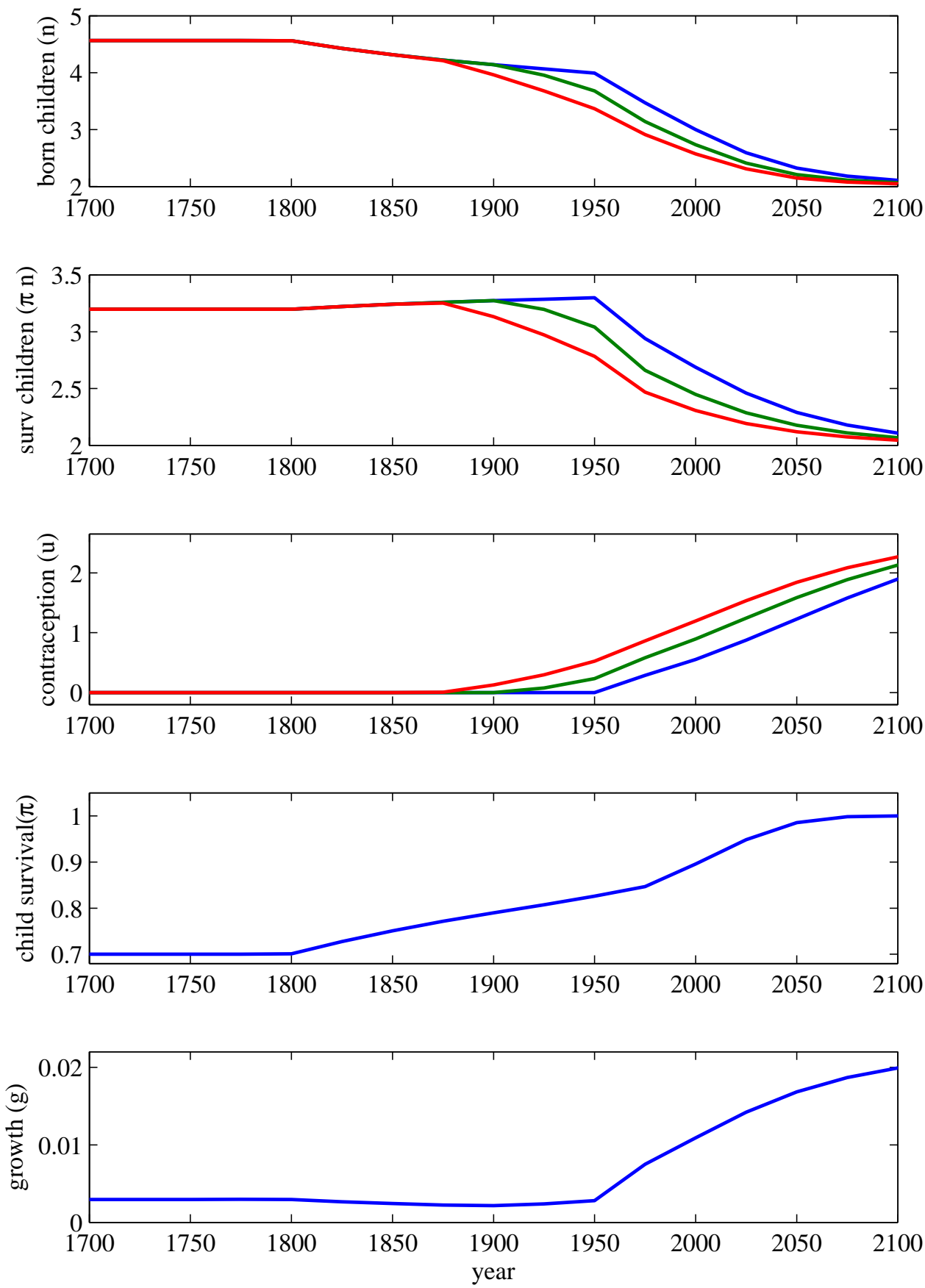

Parameter values as for Figure $3 ; 3$ population classes; initial values $h_{0}=(6,15,24)$ and $\ell_{0}=(12.5,4,1.25) . \mu$ rises from 1.46 to 1.75 in the year 1960 .

\section{Conclusion}

Inspired by insights from evolutionary psychology and from happiness economics, this paper has integrated sex in the utility function and developed a theory of demand for children and for contraceptives. The approach provides a natural explanation for a negative income fertility 
nexus and motivates an income threshold below which modern contraceptives are not used. The fertility transition commences only after the threshold has been crossed. The fertility transition is accompanied by increasing investments in child education, which further amplifies income growth and the use of contraceptives. The economy develops towards a steady state at which couples experience more sex but have fewer children than couples at the traditional equilibrium, and at which the economy grows at a (much) higher rate.

This paper provides a first attempt to integrate sexual desire and contraceptive use into unified growth theory. Several extensions of the theory are conceivable. In particular, it would be interesting to integrate a role for social interaction and cultural evolution for the demand of children and the use of contraceptives (Palivos, 1995; Kohler et al., 2001; Munshi, 2006; Iyer, 2003; Heaton, 2011). As demonstrated above, these elements are not essential to explain the transition once it is set in motion, but they are potentially useful to motivate local stability of a traditional equilibrium at which contraceptives are not used. More realism would also be gained from replacing the unitarian household by a bargaining approach and by considering not only gender-specific child demand (Eswaran, 2002) and rearing costs (De la Croix and Vander Donckt, 2010), but also gender-specific access to contraceptives. 


\section{REFERENCES}

Ainsworth, M., Beegle, K., and Nyamete, A., 1996, The impact of women's schooling on fertility and contraceptive use: A study of fourteen sub-Saharan African countries, World Bank Economic Review 10, 85-122.

Bailey, M. J., 2010, Momma's got the pill: How Anthony Comstock and Griswold v. Connecticut shaped US childbearing, American Economic Review 100(1), 98-129.

Bailey, M. J., 2013, Fifty years of family planning: new evidence on the long-run effects of increasing access to contraception, Brookings Papers on Economic Activity 2013(1), 341-409.

Bhattacharya, J. and Chakraborty, S., 2014, Contraception and the fertility transition, MPRA Discussion Paper, Munich.

Blanchflower, D.G., and Oswald, A.J., 2004, Money, sex and happiness: An empirical study, Scandinavian Journal of Economics 106, 393-415.

Bongaarts, J. and Potter, R.G., 1983, Fertility, Biology, and Behavior: An Analysis of the Proximate Determinants, New York: Academic Press.

Bongaarts, J., 1994, The impact of population policies: Comment, Population and Development Review 20, 616-620.

Brown, J.C., 2009, Fertility control with imperfect methods: Strategies of family building and the choice of technique during the German fertility transition, 1885-1915, unpublished.

Cleland, J., 2001, The effects of improved survival on fertility: A reassessment, Population and Development Review, 27(Supplement), 6092.

Cervellati, M. and Sunde, U., 2005, Human capital formation, life expectancy, and the process of development, American Economic Review 95, 1653-1672.

Darroch, J.E. and Singh, S., 2013, Trends in contraceptive need and use in developing countries in 2003, 2008, and 2012: an analysis of national surveys, Lancet 381, 1756-1762.

Deaton, A. and Stone, A.A., 2014, Evaluative and hedonic wellbeing among those with and without children at home, Proceedings of the National Academy of Sciences 111, 1328-1333.

De la Croix D. and Vander Donckt, M., 2010, Would empowering women initiate the demographic transition in least-developed countries?, Journal of Human Capital 4, 85-129.

Doepke, M., 2004, Accounting for fertility decline during the transition to growth, Journal of Economic Growth 9: 347-383.

Doepke, M., 2005, Child mortality and fertility decline: Does the BarroBecker model fit the facts?, Journal of Population Economics 18, 337366.

Eswaran, M., 2002, The empowerment of women, fertility, and child mortality: Towards a theoretical analysis, Journal of Population Economics 15, 433-454. 
Fernandez-Villaverde, J., Greenwood, J., and Guner, N., 2014, From shame to game in one hundred years: An economic model of the rise in premarital sex and its de-stigmatization, Journal of the European Economic Association 12, 25-61.

Gakidou, E., and Vayena, E., 2007, Use of modern contraception by the poor is falling behind, PLoS medicine, 4(2), e31.

Galor, O., 2005, From stagnation to growth: Unified growth theory, in: P. Aghion and S. Durlauf, Handbook of Economic Growth Vol 1A, Amsterdam, North-Holland.

Galor, O., 2011, Unified Growth Theory, Princeton University Press.

Galor, O. and Weil, D. N., 1996, The gender gap, fertility, and growth ,American Economic Review 86, 374-387.

Galor, O. and Weil, D.N., 2000, Population, technology and growth: From the Malthusian regime to the demographic transition and beyond, American Economic Review 110, 806-828.

Galor, O. and Moav, O., 2002, Natural selection and the origin of economic growth, Quarterly Journal of Economics 117, 1133-1192.

Galor, O., and Moav, O., 2006, Das human-kapital: A theory of the demise of the class structure, Review of Economic Studies 73, 85-117.

Galor, O. and Mountford, A., 2008, Trading population for productivity: Theory and evidence, Review of Economic Studies 75, 1143-1179.

Goldin, C. and Katz, L.F., 2002, The power of the pill: Oral contraceptives and women's career and marriage decisions, Journal of Political Economy 110, 730-770.

Greenwood, J., and Guner, N., 2010, Social Change: The sexual revolution, International Economic Review 51, 893-923.

Guenter, I. and Harttgen, K., 2013, Desired fertility and children born across time and space, CRC Discussion Paper, Goettingen.

Guinnane, T. W., 2011, The historical fertility transition: A guide for economists, Journal of Economic Literature 49(3), 589-614.

Haines, M.R., 1989, Social class differentials during fertility decline: England and Wales revisited, Population Studies 43, 305-323.

Haveman, R.H. and Wolfe, B.L., 1995, The determinants of children's attainments: A review of methods and findings, Journal of Economic Literature 33, 1829-1878.

Heaton, T. B., 2011, Does religion influence fertility in developing countries, Population Research and Policy Review 30, 449-465.

Herzer, D., Vollmer, S., and Strulik, H., 2012, The long-run determinants of fertility: One century of demographic change 1900-1999, Journal of Economic Growth 17, 357-385. 
ICF, 2012. ICF International. The DHS Program STATcompiler - http://www . statcompiler .com - April 12014.

Iyer, S. (2003) Religion, reproduction and development in contemporary India, Development 46, 50-56.

Jones, C.I., 2001, Was an industrial revolution inevitable? Economic growth over the very long run, Advances in Macroeconomics 1, 1-43.

Jones, L.E. and Tertilt, M., 2008, An economic history of fertility in the U.S.: 1826-1960, in: Frontiers of Family Econcomis Vol 1., P. Rupert (ed.), Emerald Press.

Jones, L.E., Schoonbroodt, A., and Tertilt, M., 2010, Fertility theories: Can they explain the negative fertility-income relationship?, in: Demography and the Economy, University of Chicago Press, 43-100.

Kahneman, D., Krueger, A. B., Schkade, D., Schwarz, N., and Stone, A., 2004, Toward national well-being accounts, American Economic Review 94(2), 429-434.

Kalemli-Ozcan, S., 2002, Does the mortality decline promote economic growth, Journal of Economic Growth 7: 411-439.

Kalemli-Ozcan, S., 2003, A Stochastic Model of Mortality, Fertility, and Human Capital Investment, Journal of Development Economics 70, 10318.

Kögel, T. and Prskawetz, A., 2001, Agricultural productivity growth and escape from the Malthusian trap, Journal of Economic Growth 6, 337-357.

Kohler, H. P., Behrman, J. R., and Watkins, S. C., 2001, The density of social networks and fertility decisions: Evidence from South Nyanza District, Kenya, Demography 38, 43-58.

Lucas, R.E., 2002, The Industrial Revolution: Past and Future, Cambridge: Harvard University Press.

Lule, E., Singh, S., and Chowdhury, S.A., 2007, Fertility Regulation Behaviors and Their Costs: Contraception and Unintended Pregnancies in Africa and Eastern Europe 89 Central Asia, World Bank, Washington DC.

Livi-Bacci, M., 1986, Social-group forerunners of fertility control in Europe, in: A.J. Coale and S.C. Watkins (eds.) The Decline of Fertility in Europe, Princeton: Princeton University Press.

Margolis, R. and Myrskyl, M., 2011, A global perspective on happiness and fertility, Population and Development Review 37, 29-56.

Mosher W.D., Martinez G.M., Chandra A., et al., 2004, Use of contraception and use of family planning services in the United States, 1982-2002. US Department of Health and Human Services, Centers for Disease Control and Prevention, National Center for Health Statistics, 2004.

Munshi, K. and Myaux, J., 2006, Social norms and the fertility transition, Journal of Development Economics 80, 1-38. 
Palivos, T., 1995, Endogenous fertility, multiple growth paths, and economic convergence, Journal of Economic Dynamics and Control 19, 1489-1510.

Pritchett, L.H., 1994, Desired fertility and the impact of population policies, Population and Development Review 20, 1-55.

and Place 10, 19-41.

Seccombe, W., 1990, Starting to stop: Working-class fertility in Britain, Past and Present 126, 151-188.

Strulik, H. and Weisdorf, J., 2008, Population, food, and knowledge: A simple unified growth model, Journal of Economic Growth 13, 169-194.

Strulik, H., Prettner, K., and Prskawetz, A., 2013, The Past and Future of Knowledge-based Growth, Journal of Economic Growth 18, 411-437.

Westoff, C. F., and Bankole, A., 2001, The contraception-fertility link in sub-Saharan Africa and in other developing countries, DHS Analytical Studies 4, Calverton, Maryland: ORC Macro.

Woods, R., 2000, The Demography of Victorian England and Wales, Cambridge University Press.

World Bank, 2007, Population Issues in the 21st Century: The Role of the World Bank, Washington DC: World Bank.

Wright, R., 1994, The Moral Animal, Random House, New York. 